\title{
Inhibition effect of triptolide on human epithelial ovarian cancer via adjusting cellular immunity and angiogenesis
}

\author{
HUI HU ${ }^{1 *}$, GENHUA HUANG ${ }^{1 *}$, HAIBIN WANG ${ }^{1}$, XIAOLI LI ${ }^{1}$, XIAOBING WANG ${ }^{1}$, \\ YING FENG $^{1}$, BUZHEN TAN ${ }^{1}$ and TINGTAO CHEN $^{2}$ \\ ${ }^{1}$ Department of Obstetrics and Gynecology, The Second Affiliated Hospital of Nanchang University, Nanchang, \\ Jiangxi 330006; ${ }^{2}$ Institute of Translational Medicine, Nanchang University, Nanchang, Jiangxi 330031, P.R. China
}

Received August 1, 2017; Accepted December 13, 2017

DOI: $10.3892 /$ or.2017.6158

\begin{abstract}
Chemotherapy resistance of advanced ovarian cancers is responsible for death of most cancer patients, so it is necessary to seek safe and effective natural ingredients to lower the chemotherapy resistance of ovarian cancer. In the present study, we studied the anticancer effects of triptolide (TPL) and TPL + cisplatin (DDP) in vitro and in vivo using SKOV3/DDP cell line and a mouse model. In vitro results showed that TPL and TPL + DDP inhibited cellular invasion and migration of SKOV3/DDP cells $(\mathrm{P}<0.05)$, and significantly reduced the expression of adhesion-related proteins integrin $\beta 1$ (ITG $\beta 1$ ) and apoptosis-inhibiting proteins survivin, matrix metalloproteinase $2(\mathrm{MMP}-2)$ and MMP-9 $(\mathrm{P}<0.05)$. Animal results demonstrated that TPL and TPL + DDP had significantly enhanced the inflammatory factor-2 (IL-2) and tumor necrosis factor- $\alpha(\mathrm{TNF}-\alpha)$ in serum of mice, and significantly increased the NK cell-related protein levels of CD16 and CD56, while significantly inhibited the production of vascular endothelial growth factor (VEGF) related protein clusters of differentiation 31 (CD31) and CD105. Collectively, the combination of TPL and DDP may produce a synergistic anticancer effect on epithelial ovarian cancer (EOC).
\end{abstract}

Correspondence to: Dr Buzhen Tan, Department of Obstetrics and Gynecology, The Second Affiliated Hospital of Nanchang University, Nanchang, Jiangxi 330006, P.R. China

E-mail: tanbuzhen@sina.com

Dr Tingtao Chen, Institute of Translational Medicine, Nanchang University, Nanchang, Jiangxi 330031, P.R. China

E-mail: chentingtao1984@163.com

*Contributed equally

Key words: epithelial ovarian cancer, triptolide, cisplatin, SKOV3/DDP cells

\section{Introduction}

Epithelial ovarian cancer (EOC) is regarded as the most common type of ovarian cancers, which is usually diagnosed at an advanced stage due to the ineffective screening strategies, and causes immense morbidity and mortality worldwide (1). Although the surgical resection combined with cisplatin-based chemotherapy has greatly benefited cancer patients, the total survival of patients with advanced disease is $<30 \%$ due to chemoresistance $(2,3)$. Therefore, it is meaningful to find the sensitizer of EOC to cisplatin and clarify its mechanisms.

Numerous studies indicate that the mechanism of tumor occurrence, development, invasion, metastasis and resistance is complex (4-9). As one of the most well-known natural products, triptolide (TPL) had been used as an anti-inflammatory agent for rheumatoid arthritis for a long time in China, and was also recognized as a potential medicine for various types of cancers (10-16) although some researchers showed its potential toxicity on animal liver, kidney, testes, ovary and heart (17). Recent studies indicated that TPL induced cell apoptosis by inhibiting nuclear factor $\kappa$-light-chain-enhancer of activated B cells $(\mathrm{NF}-\kappa \mathrm{B})$ in a p53-independent pathway, producing reactive oxygen species (ROS) and inactivating the PI3K/Akt signal pathway $(9,16,18-21)$. In previous studies, our group proved that the TPL effectively inhibited cell growth, proliferation, metabolism, survival and cancer genesis by regulating the PI3K/Akt pathway (22). However, scarce study is carried out to evaluate the antitumor effect of TPL on cellular immunity and angiogenesis.

In the present study, we investigated the TPL anticancer effects using SKOV3/DDP cell line and a mouse model, and studied the TPL sensitization effects via inhibiting protein expression of angiogenesis and immunology.

\section{Materials and methods}

Cell experiments. Platinum-resistant SKOV3/DDP cell line (purchased from China Center for Type Culture Collection, Wuhan, China), which was derived from human ovarian carcinoma, was cultured in RPMI-1640 medium containing $10 \%$ fetal bovine serum (FBS) and $100 \mathrm{U} / \mathrm{ml}$ penicillin/streptomycin. Cells were cultured at $37^{\circ} \mathrm{C}$ in a $5 \%$ humidified $\mathrm{CO}_{2}$ 
atmosphere, and $0.3 \mu \mathrm{g} / \mathrm{ml}$ cisplatin was added to the culture media to maintain the acquired resistance to DDP.

Cellular migration and invasion assays. To evaluate the effect of TPL on cell migration, a scratch assay was applied. SKOV3/DDP cells were seeded onto 6-well plates to make a confluent monolayer, and then a p200 pipette tip was used to create a straight line to make a 'scratch'. Suspended cells were washed using PBS, then $200 \mu 1$ RPMI-1640 medium containing $2 \%$ FBS was added. SKOV3/DDP cells were co-cultured with $10 \mu \mathrm{g} / \mathrm{ml}$ DDP, $8 \mathrm{ng} / \mathrm{ml} \mathrm{TPL}$ and $10 \mu \mathrm{g} / \mathrm{ml}$ DDP $+8 \mathrm{ng} / \mathrm{ml}$ TPL for $24 \mathrm{~h}$. The wound area was calculated using Image-Pro Plus software (IPP; Media Cybernetics, Rockville, MD, USA).

For cell invasion assay, SKOV3/DDP cells $\left(5 \times 10^{4}\right.$ cells/well $)$ were seeded to the upper chamber of the Transwell plates (Corning Life Sciences, Lowell, MA, USA) and co-cultured with RPMI-1640 media containing 2\% FBS, and $500 \mu 1$ RPMI-1640 media supplemented with 10\% FBS were added into the bottom wells. Then, $10 \mu \mathrm{g} / \mathrm{ml}$ DDP, $8 \mathrm{ng} / \mathrm{ml} \mathrm{TPL}$ and $10 \mu \mathrm{g} / \mathrm{ml} \mathrm{DDP}+8 \mathrm{ng} / \mathrm{ml}$ TPL were added to the chambers, respectively. Incubated for $24 \mathrm{~h}$, the SKOV3/DDP cells that invaded through the Matrigel matrix membrane were stained with crystal violet for 30-40 min, and their number was counted using an inverted microscope.

Apoptosis analysis. The treated SKOV3/DDP cells were digested using trypsin and washed twice using cold Hanks' solution. Then, SKOV3/DDP cells were suspended in a binding buffer containing Annexin V-FITC and PI. The cell mixture was incubated at room temperature (RT) (in dark) for $15 \mathrm{~min}$, and were then sorted by cell flow cytometry (Becton-Dickinson, San Jose, CA, USA).

Western blotting. Cell lysis buffer supplemented with protease inhibitor cocktail and $1 \mathrm{mM}$ phenylmethanesulfonyl fluoride (PMSF) were used to prepare whole-cell lysates, and protein concentrations were measured (10). Then, samples were resolved by polyacrylamide electrophoresis, the polyvinylidene difluoride membranes were blocked with 5\% non-fat milk in TBST for $1 \mathrm{~h}$ at RT, and were incubated with primary antibodies for $3 \mathrm{~h}$ at RT, and then incubated with the appropriate HRP-conjugated secondary antibody for another $1 \mathrm{~h}$.

Mouse model of ovarian cancer. To establish primary tumor xenografts, five million SKOV3/DDP cells were injected in the $\mathrm{BALB} / \mathrm{c}-$ nu nude mice in a volume of $20 \mu \mathrm{l}$ of PBS. When tumors reached $100 \mathrm{~mm}^{3}$, PBS (50 ml/kg/day, every day), DDP (4 mg/kg/day on the 1st and 8th days), TPL ( $0.15 \mathrm{mg} / \mathrm{kg} /$ day every day), DDP + TPL (4 mg/kg/day of DDP on the 1st and 8th days, $0.15 \mathrm{mg} / \mathrm{kg} / \mathrm{day}$ of TPL every day) was injected i.p. into the mice. In the end, all mice were cervically sacrificed and their orbital blood were collected.

The present study was approved by the Ethics Committee of the Second Affiliated Hospital of Nanchang University, and all the research was carried out based on the approved guidelines.

ELISA. The yields of IL-2 and TNF- $\alpha$ in mouse sera were evaluated using the IL-2 ELISA kit) and TNF- $\alpha$ ELISA kit (both from eBioscience, San Diego, CA, USA).
Immunohistochemical staining. Resected tumors were fixed in the $10 \%$ buffered formalin, and then embedded in paraffin and mounted on slides. Tumor sections were paraffinized and suppressed in endogenous peroxidase activity incubation in $3 \%$ hydrogen peroxide, and were microwaved in $10-\mathrm{mM}$ sodium citrate $(\mathrm{pH} 6.0)$ to achieve the antigen retrieval. Then, $2.5 \%$ horse serum were used to block sections, and corresponding antibodies were used and incubated for $16 \mathrm{~h}$ at $4^{\circ} \mathrm{C}$. 3,3'-Diaminobenzidine and hematoxylin were used to stain slides, and detection was achieved using Avidin-Biotin Complex System (Vector Laboratories, Burlingame, CA, USA), which was analyzed using the IPP based on their density mean, area sum and integrated optical density.

Statistical analysis. The data are presented as mean \pm SD, $\mathrm{P}<0.05$ was considered statistically significant (23-25).

\section{Results}

Effects of TPL and DDP + TPL on migration and invasion of SKOV3/DDP cells. To the best of our knowledge, cellular invasion is an important part of cellular migration. Cells with high migration usually possess high invasion, while cells with high invasion may not possess high migration. So we simultaneously tested the migration and invasion of SKOV3/DDP cells. As shown in Fig. 1, the addition of DDP, TPL and DDP + TPL significantly reduced the cellular invasion and migration of SKOV3/DDP compared with the control group $(\mathrm{NC})$ at $24 \mathrm{~h}(\mathrm{P}<0.05)$, and the synergistic effect of TPL and DDP had significantly enhanced the inhibition effect on cellular invasion and migration compared with DDP and TPL group $(\mathrm{P}<0.05)$.

$T P L+D D P$ increases the apoptosis rate of SKOV3/DDP cells. When treated with different concentrations of reagents, the apoptosis rates in the control, DDP, TPL and TPL+DDP group were $(4.863 \pm 0.930),(8.333 \pm 0.965),(19.823 \pm 2.558)$ and $(24.733 \pm 2.009) \%$, respectively. For the single drug group, DDP and TPL greatly enhanced the apoptosis rate of SKOV3/DDP cells $(\mathrm{P}<0.05)$, and the TPL + DDP had the best promoting effect on apoptosis of SKOV3/DDP cells compared with DDP and TPL group $(\mathrm{P}<0.05)$ (Fig. 2).

Effects of TPL and DDP + TPL on protein expression of SKOV3/DDP cells. As tumor development is a complex process, so cancer-related proteins were tested. As shown in Fig. 3, the treatment of DDP, TPL and DDP + TPL significantly reduced the expression of adhesion-related protein integrin $\beta 1$ (ITG $\beta 1$ ) and apoptosis-inhibiting proteins survivin, matrix metalloproteinase 2 (MMP-2) and MMP-9 (DDP + TPL group $>$ TPL $>$ DDP; $P<0.05$ ), and significantly increased the yields of apoptosis-promoting proteins cleaved caspase- 3 and Smac (DDP+TPL group $>$ TPL $>$ DDP; P $<0.05$ ).

Effects of TPL and DDP + TPL on IL-2 and TNF- $\alpha$ expression. To further study the anticancer effects of TPL and DDP + TPL on tumors, the DDP, TPL and DDP + TPL were intraperitoneally injected or orally administered to mice, and their effects on related cytokines were evaluated. As shown in Fig. 4, the $4 \mathrm{mg} / \mathrm{kg} /$ day DDP, $0.15 \mathrm{mg} / \mathrm{kg} /$ day TPL, 

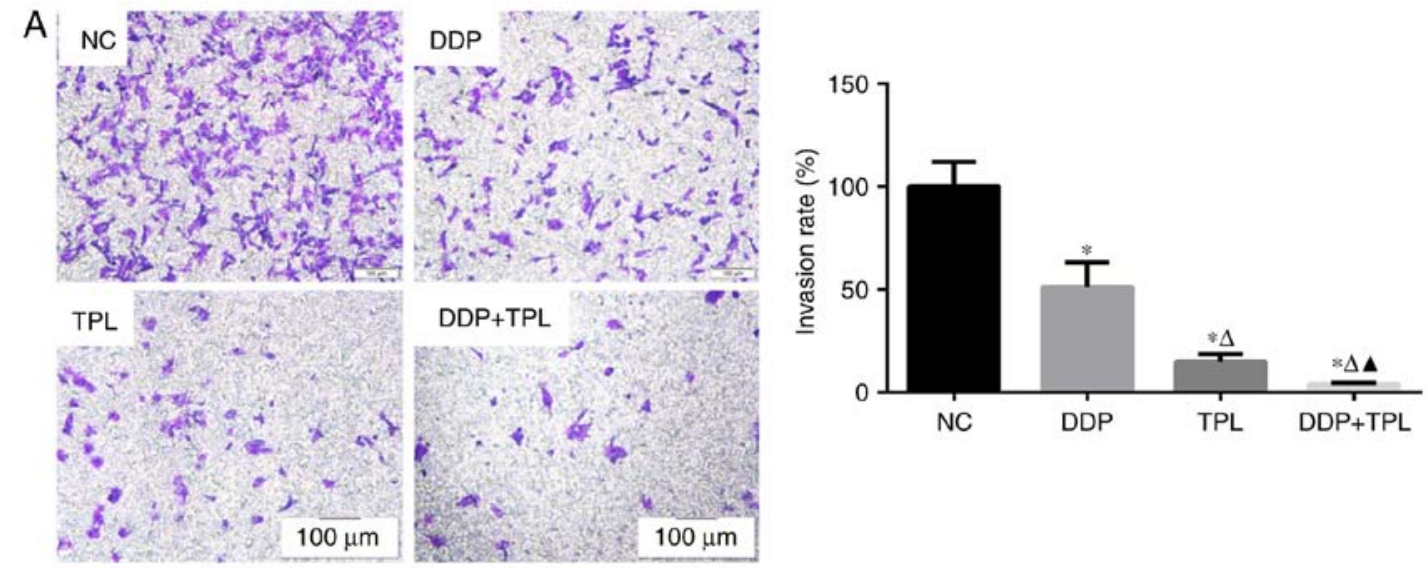

B

NC

DDP

TPL

DDP+TPL
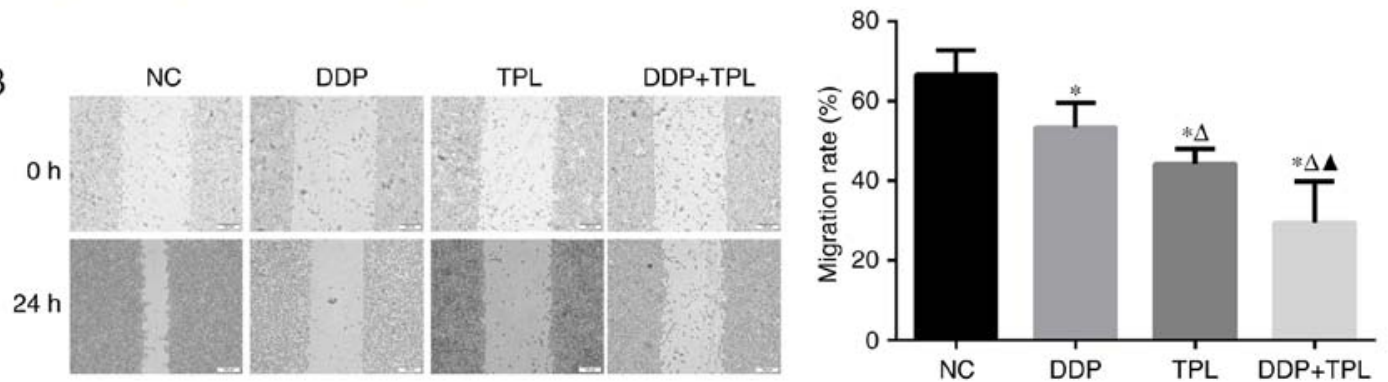

Figure 1. Effects of DDP, TPL and DDP+TPL on (A) cancer cell invasion and (B) cancer cell migration. The DDP, TPL and DDP+TPL reduce the cellular invasion and migration of SKOV3/DDP cells, and the DDP + TPL possessed the best inhibition effect. Compared with blank group, "P<0.05; compared with TPL group, ${ }^{\Delta} \mathrm{P}<0.05$; compared with DDP group, ${ }^{\wedge} \mathrm{P}<0.05$.
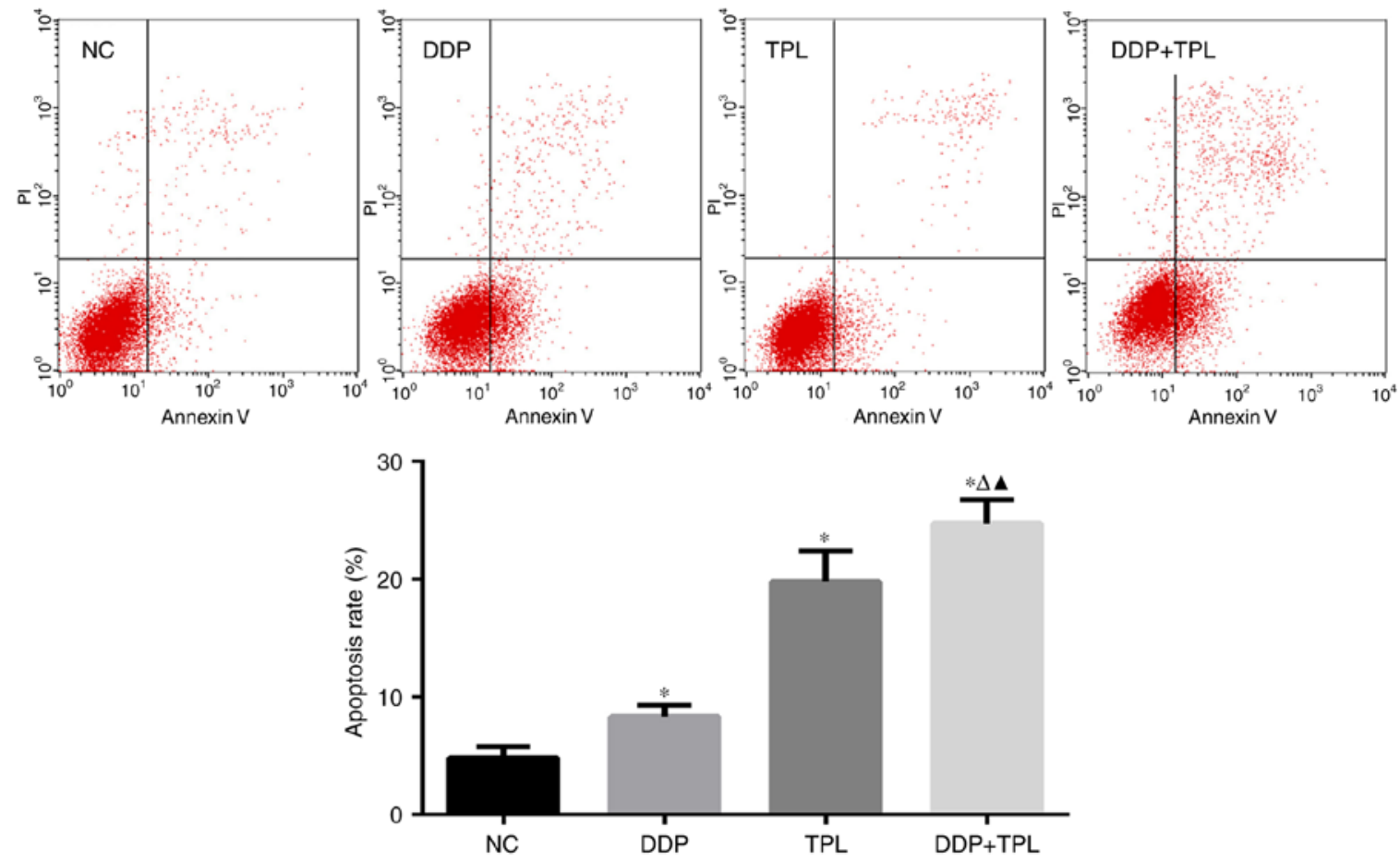

Figure 2. Effect of DDP, TPL and DDP+TPL on apoptosis of SKOV3/DDP cells ( $\bar{x} \pm s, \mathrm{n}=3)$. Both the DDP group and TPL group can promote the apoptosis rate of SKOV3/DDP cells, and TPL+DDP had the best apoptosis rate of $24.733 \%$ among the groups. Compared with blank group, "P $<0.05$; compared with TPL group, ${ }^{\wedge} \mathrm{P}<0.05$; compared with DDP group, ${ }^{\mathbf{\Lambda}} \mathrm{P}<0.05$.

$4 \mathrm{mg} / \mathrm{kg} /$ day TPL and $0.15 \mathrm{mg} / \mathrm{kg} /$ day TPL greatly enhanced the inflammatory factors IL-2 and TNF- $\alpha$ in serum, and the DDP+TPL possessed the best enhancement effects compared to the other two groups.
Effects of TPL and DDP + TPL on protein expression of cellular immunity and angiogenesis. To find the synergistic mechanisms of TPL and DDP, proteins related to tumor immunity and angiogenesis were studied in control, DDP, TPL, and 

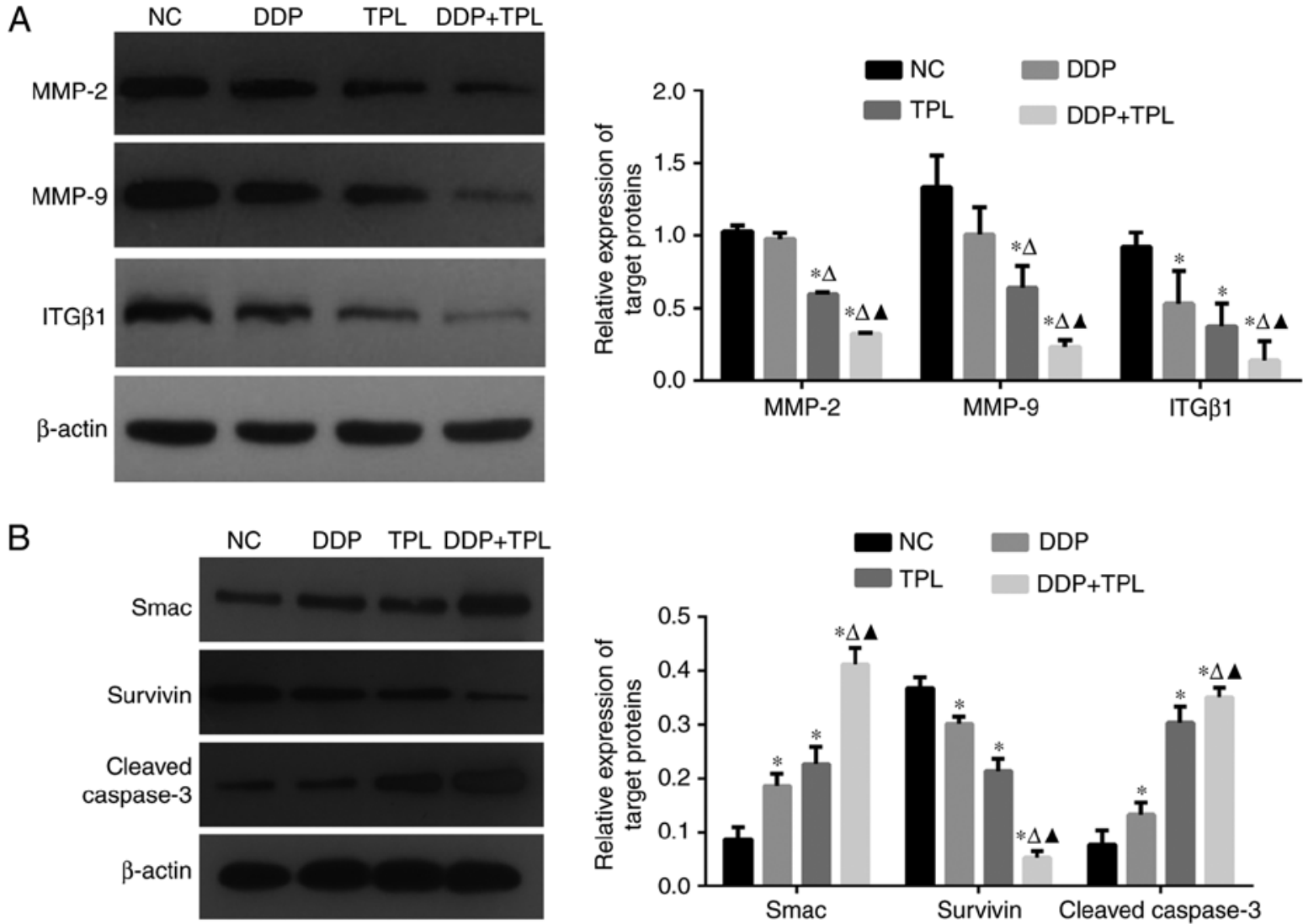

Figure 3. (A) Effects of DDP, TPL and DDP + TPL on protein expression profiles of MMP-2, MMP-9, ITG $\beta 1$ and $\beta$-actin; (B) Effects of DDP, TPL and DDP+TPL on protein expression profiles of Smac, survivin, cleaved caspase- 3 and $\beta$-actin. The DDP+TPL significantly reduced the production of ITG $\beta 1$, MMP-2 and MMP-9, and significantly enhanced the yield of cleaved caspase- 3 and Smac. Compared with blank group, ${ }^{*} \mathrm{P}<0.05$; compared with TPL group, ${ }^{\wedge} \mathrm{P}<0.05 ;$ compared with DDP group, ${ }^{\wedge} \mathrm{P}<0.05$.

A

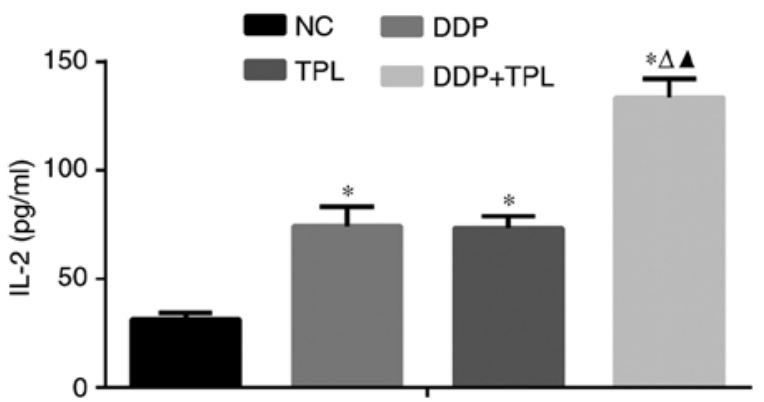

B

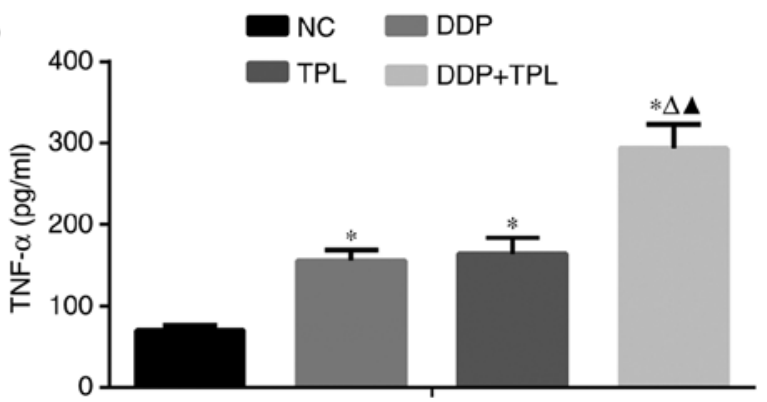

Figure 4. (A) Effects of DDP, TPL and DDP+TPL on the expression of IL-2. (B) Effects of DDP, TPL and DDP+TPL on the expression of TNF- $\alpha$. Data indicate that DDP + TPL significantly enhanced the production of IL-2 and TNF- $\alpha$. Compared with blank group, ${ }^{*} \mathrm{P}<0.05$; compared with TPL group, ${ }^{\Delta} \mathrm{P}<0.05$; compared with DDP group, ${ }^{\mathbf{A}} \mathrm{P}<0.05$.

TPL+DDP groups. As shown in Fig. 5, the NK cell-related protein levels of CD16 and CD56 obviously increased in treatment groups, and the TPL + DDP had the best effect. Moreover, the addition of DDP, TPL and DDP + TPL greatly inhibited the production of vascular endothelial growth factor (VEGF) related proteins CD31 and CD105 (DDP + TPL group > TPL group $>$ DDP group)

\section{Discussion}

The platinum-based chemotherapy combined with curative resection was widely used in various cancer treatments, while drug resistance to DDP has emerged as the major hinderence to this method (26), thus naturally-occurring, plant-derived compounds have become a research hotspot in cancer therapies, which have been proven to influence multiple signaling pathways and can enhance the activity of conventional chemotherapy and radiation therapy (27).

As one of the well-known phytochemicals, TPL has been investigated for its pleiotropic anticancer activities by inhibiting cancer cell proliferation and inducing apoptosis of various cancers $(11,12,16,28-35)$, while few studies were carried out on the effect of TPL on the cellular immunity and angiogenesis of human epithelial ovarian cancer (EOC). 


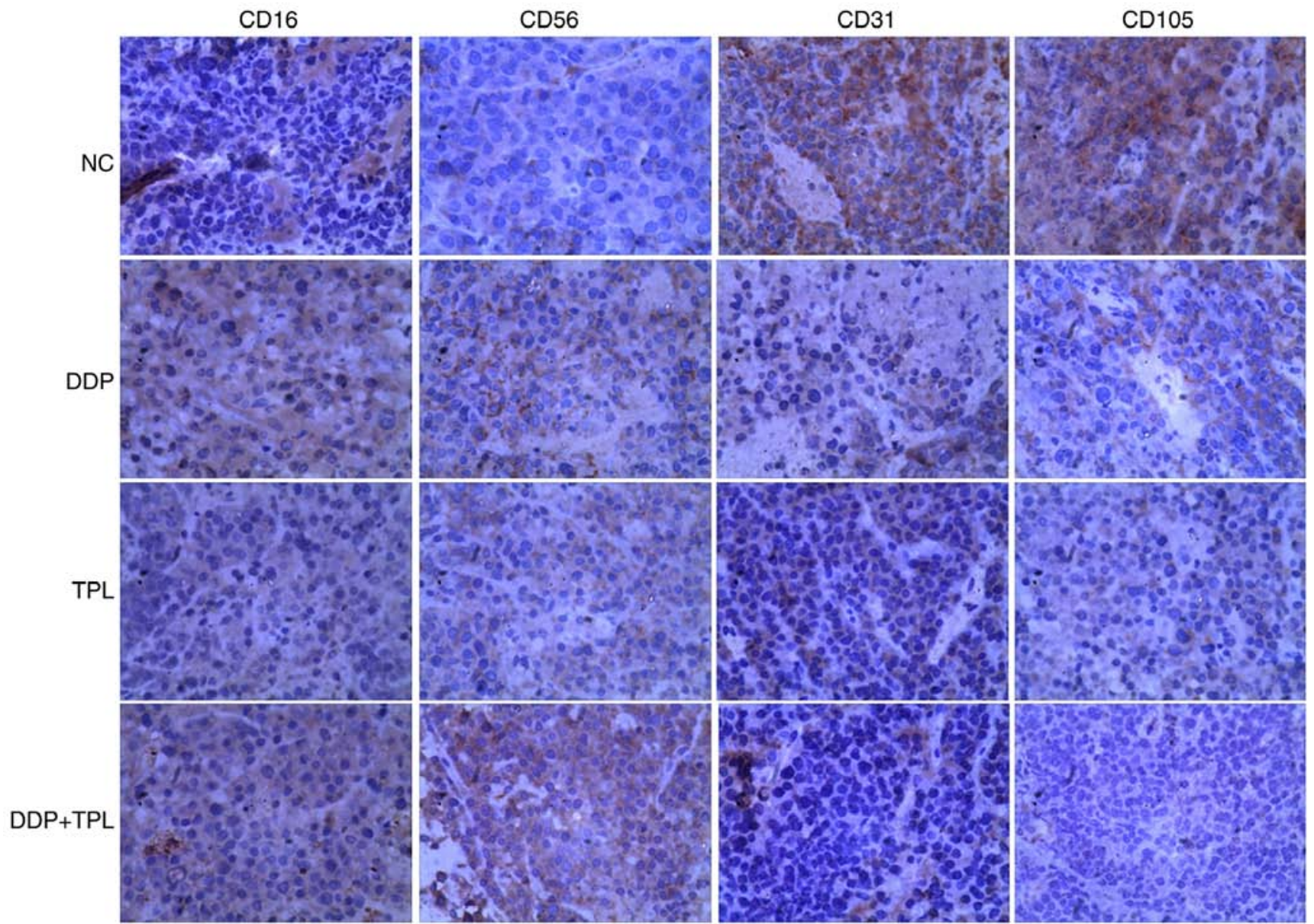

Figure 5. Effects of DDP, TPL and DDP + TPL on the expression of CD16, CD56, CD31 and CD105 using immunohistochemical method (at $4 * \mathrm{C})$. The combination of TPL and DDP can greatly increase the NK cell related proteins (CD16 and CD56) and can obviously reduce the vascular endothelial growth factor (VEGF) related proteins (CD31 and CD105) to inhibit tumor growth.

In the present study, we first evaluated the combination of DDP and TPL on cell invasion, migration and apoptosis of cisplatin-resistance cell SKOV3/DDP in vitro, and determined the combined effects of DDP and TPL. The expected value of combination effect between DDP and TPL was calculated as: [(observed DDP value)/(control value)] x [(observed TPL value)/(control value)] $\mathrm{x}$ (control value); and the combination index is calculated as the ratio of (expected value)/(observed DDP+TPL value), and the ratio of $>1$ indicated a synergistic effect (36). As the ratio of the combination of DDP + TPL was $>1$, thus, they presented a synergistic effect on the inhibition of human EOC. Our results indicated that the DDP+TPL group significantly inhibited the invasion and migration of SKOV3/DDP cells compared with DDP and TPL group, and the apoptosis rate in DDP + TPL group was as high as $(24.733 \pm 2.009) \%$ (Figs. 1 and 2). Moreover, the western blot results confirmed that addition of TPL to DDP group greatly enhanced the yields of apoptosis-promoting proteins of cleaved caspase- 3 and Smac, and obviously reduced the production of ITG $\beta 1$, survivin, MMP-2 and MMP-9 $(\mathrm{P}<0.05)$. As is known, caspase-3 belongs to the cysteine protease family, playing a key role in apoptotic pathways via cleaving a series of key cellular proteins, while survivin is a member of the inhibitor of apoptosis (IAP) family to inhibit caspase activation (37), and Smac is a member of promoter for caspase activation via binding to inhibitors of apoptosis-related proteins (38), therefore the negative regulation of survivin and positive regulation of Smac to caspase-3 lead to apoptosis (programmed cell death) of SKOV3/DDP cells.

In addition, the significant reduction of the membrane protein ITG $\beta 1$ (39) (a key protein in tumor invasion and metastasis, via mediating the adhesion of cells to the matrix and regulating the adhesion growth, migration, invasion and angiogenesis and chemotherapy resistance of many tumor cells) and MMP-2/MMP-9 (40) (whose altered expression and activity levels had been strongly implicated in the progression and metastasis of many forms of cancers) contributed to tumor apoptosis and tumor suppression. Fig. 4 shows the DDP + TPL greatly enhanced expression of IL-2 (which promotes the differentiation of $\mathrm{T}$ cells into effector $\mathrm{T}$ cells and into memory T cells to enhance the immunity of host) and TNF- $\alpha$ (whose primary role is to regulate immune cells, and is able to inhibit tumorigenesis), creating a inflammatory environment to promote the death of cancer cells $(41,42)$.

In conclusion, our results indicated that both the TPL and DDP + TPL greatly enhanced cell apoptosis and tumor suppression via adjusting cellular immunity and angiogenesis of human EOC. Therefore, we proposed that TPL can lower the resistance of EOC to cisplatin, and can serve as a promising reagent for the treatment of human ovarian cancer. 


\section{Acknowledgements}

The present study was supported by grants from the National Natural Science Foundation of China (nos. 81760729, 81503364 and 31560264), and the Jiangxi Government (20161BBG70218, 2016A078, 20171BCB23028 and 20175526).

\section{References}

1. Cannistra SA: Cancer of the ovary. New Engl J Med 351: 2519-2529, 2004.

2. Shepherd JE: Current strategies for prevention, detection, and treatment of ovarian cancer. J Am Pharm Assoc 40: 392-401, 2000.

3. Agarwal R and Kaye SB: Ovarian cancer: Strategies for overcoming resistance to chemotherapy. Nat Rev Cancer 3: 502-516, 2003.

4. Haynes-Gimore N, Banach M, Brown E, Dawes R, Edholm ES, Kim M and Robert J: Semi-solid tumor model in Xenopus laevis/gilli cloned tadpoles for intravital study of neovascularization, immune cells and melanophore infiltration. Dev Biol 408: 205-212, 2015.

5. Facciabene A, Motz GT and Coukos G: T-regulatory cells: Key players in tumor immune escape and angiogenesis. Cancer Res 72: 2162-2171, 2012.

6. Zhou R, He PL, Ren YX, Wang WH, Zhou RY, Wan H, Ono S, Fujiwara $\mathrm{H}$ and Zuo JP: Myeloid suppressor cell-associated immune dysfunction in CSA1M fibrosarcoma tumor-bearing mice. Cancer Sci 98: 882-889, 2007.

7. Kiessling R, Wasserman K, Horiguchi S, Kono K, Sjöberg J, Pisa $\mathrm{P}$ and Petersson M: Tumor-induced immune dysfunction. Cancer Immunol Immunother 48: 353-362, 1999.

8. Liu Z, Yun R, Yu X, Hu H, Huang G, Tan B and Chen T: Overexpression of Notch 3 and pS6 is associated with poor prognosis in human ovarian epithelial cancer. Mediators Inflamm 2016: 5953498, 2016.

9. Hu H, Luo L, Liu F, Zou D, Zhu S, Tan B and Chen T: Anti-cancer and sensibilisation effect of triptolide on human epithelial ovarian cancer. J Cancer 7: 2093-2099, 2016.

10. Johnson SM, Wang X and Evers BM: Triptolide inhibits proliferation and migration of colon cancer cells by inhibition of cell cycle regulators and cytokine receptors. J Surg Res 168: 197-205, 2011.

11. Shu B, Duan W, Yao J, Huang J, Jiang Z and Zhang L: Caspase 3 is involved in the apoptosis induced by triptolide in HK-2 cells. Toxicol In Vitro 23: 598-602, 2009.

12. Manzo SG, Zhou ZL, Wang YQ, Marinello J, He JX, Li YC, Ding J, Capranico G and Miao ZH: Natural product triptolide mediates cancer cell death by triggering CDK7-dependent degradation of RNA polymerase II. Cancer Res 72: 5363-5373, 2012.

13. Shao H, Ma J, Guo T and Hu R: Triptolide induces apoptosis of breast cancer cells via a mechanism associated with the Wnt/ $\beta$ catenin signaling pathway. Exp Ther Med 8: 505-508, 2014.

14. Li H, Pan GF, Jiang ZZ, Yang J, Sun LX and Zhang LY: Triptolide inhibits human breast cancer MCF-7 cell growth via downregulation of the ER $\alpha$-mediated signaling pathway. Acta Pharmacol Sin 36: 606-613, 2015.

15. Ziaei S and Halaby R: Immunosuppressive, anti-inflammatory and anti-cancer properties of triptolide: A mini review. Avicenna J Phytomed 149-164, 2016.

16. Zhong YY, Chen HP, Tan BZ, Yu HH and Huang XS: Triptolide avoids cisplatin resistance and induces apoptosis via the reactive oxygen species/nuclear factor- $\kappa \mathrm{B}$ pathway in SKOV3 ${ }^{\mathrm{PT}}$ platinum-resistant human ovarian cancer cells. Oncol Lett 6: 1084-1092, 2013.

17. Xi C, Peng S, Wu Z, Zhou Q and Zhou J: Toxicity of triptolide and the molecular mechanisms involved. Biomed Pharmacother 90: 531-541, 2017.

18. Kim MJ, Lee TH, Kim SH, Choi YJ, Heo J and Kim YH: Triptolide inactivates Akt and induces caspase-dependent death in cervical cancer cells via the mitochondrial pathway. Int J Oncol 37: 1177-1185, 2010.

19. Lee KY, Park JS, Jee YK and Rosen GD: Triptolide sensitizes lung cancer cells to TNF-related apoptosis-inducing ligand (TRAIL)-induced apoptosis by inhibition of NF-kappaB activation. Exp Mol Med 34: 462-468, 2002.
20. Zhu W, Hu H, Qiu P and Yan G: Triptolide induces apoptosis in human anaplastic thyroid carcinoma cells by a p53-independent but NF-кB-related mechanism. Oncol Rep 22: 1397-1401, 2009.

21. Morgan MJ and Liu ZG: Crosstalk of reactive oxygen species and NF- $\kappa$ B signaling. Cell Res 21: 103-115, 2011.

22. Zeng C, Chen T, Zhang Y and Chen Q: Hedgehog signaling pathway regulates ovarian cancer invasion and migration via adhesion molecule CD24. J Cancer 8: 786-792, 2017.

23. Ye YZ, Zhang ZH, Fan XY, Xu XL, Chen ML, Chang BW and Zhang YB: Notch3 overexpression associates with poor prognosis in human non-small-cell lung cancer. Med Oncol 30: 595, 2013.

24. Mirone G, Perna S, Shukla A and Marfe G: Involvement of Notch-1 in resistance to regorafenib in colon cancer cells. J Cell Physiol 231: 1097-1105, 2016

25. Yuan X, Wu H, Xu H, Xiong H, Chu Q, Yu S, Wu GS and Wu K: Notch signaling: An emerging therapeutic target for cancer treatment. Cancer Lett 369: 20-27, 2015.

26. Berkenblit A and Cannistra SA: Advances in the management of epithelial ovarian cancer. J Reprod Med 50: 426-438, 2005.

27. Aggarwal BB, Sethi G, Baladandayuthapani V, Krishnan S and Shishodia S: Targeting cell signaling pathways for drug discovery: An old lock needs a new key. J Cell Biochem 102: 580-592, 2007.

28. Yang M, Huang J, Pan HZ and Jin J: Triptolide overcomes dexamethasone resistance and enhanced PS-341-induced apoptosis via PI3k/Akt/NF- $\mathrm{B}$ pathways in human multiple myeloma cells. Int J Mol Med 22: 489-496, 2008.

29. Chen YW, Lin GJ, Chuang YP, Chia WT, Hueng DY, Lin CK, Nieh S and Sytwu HK: Triptolide circumvents drug-resistant effect and enhances 5-fluorouracil antitumor effect on KB cells. Anticancer Drug 21: 502-513, 2010.

30. Carter BZ, Mak DH, Schober WD, McQueen T, Harris D, Estrov Z, Evans RL and Andreeff M: Triptolide induces caspasedependent cell death mediated via the mitochondrial pathway in leukemic cells. Blood 108: 630-637, 2006.

31. Wang Z, Jin H, Xu R, Mei Q and Fan D: Triptolide downregulates Racl and the JAK/STAT3 pathway and inhibits colitis-related colon cancer progression. Exp Mol Med 41: 717-727, 2009.

32. Yang S, Chen J, Guo Z, Xu XM, Wang L, Pei XF, Yang J, Underhill CB and Zhang L: Triptolide inhibits the growth and metastasis of solid tumors. Mol Cancer Ther 2: 65-72, 2003.

33. Antonoff MB, Chugh R, Borja-Cacho D, Dudeja V, Clawson KA, Skube SJ, Sorenson BS, Saltzman DA, Vickers SM and Saluja AK: Triptolide therapy for neuroblastoma decreases cell viability in vitro and inhibits tumor growth in vivo. Surgery 146: 282-290, 2009.

34. Li CJ, Chu CY, Huang LH, Wang MH, Sheu LF, Yeh JI and Hsu HY: Synergistic anticancer activity of triptolide combined with cisplatin enhances apoptosis in gastric cancer in vitro and in vivo. Cancer Lett 319: 203-213, 2012

35. Miyata Y, Sato T and Ito A: Triptolide, a diterpenoid triepoxide, induces antitumor proliferation via activation of c-Jun $\mathrm{NH}$ 2-terminal kinase 1 by decreasing phosphatidylinositol 3-kinase activity in human tumor cells. Biochem Biophys Res Commun 336: 1081-1086, 2005.

36. Zhou JR, Yu L, Mai Z and Blackburn GL: Combined inhibition of estrogen-dependent human breast carcinoma by soy and tea bioactive components in mice. Int J Cancer 108: 8-14, 2004.

37. Altieri DC: Molecular cloning of effector cell protease receptor-1, a novel cell surface receptor for the protease factor Xa. J Biol Chem 269: 3139-3142, 1994.

38. Petersen SL, Wang L, Yalcin-Chin A, Li L, Peyton M, Minna J, Harran $\mathrm{P}$ and Wang X: Autocrine TNFalpha signaling renders human cancer cells susceptible to Smac-mimetic-induced apoptosis. Cancer Cell 12: 445-456, 2007.

39. Xu Y, Jin X, Huang Y, Dong J, Wang H, Wang X and Cao X: Inhibition of peritoneal metastasis of human gastric cancer cells by dextran sulphate through the reduction in HIF-1 $\alpha$ and ITG $\beta 1$ expression. Oncol Rep 35: 2624-2634, 2016.

40. Overall CM and López-Otín C: Strategies for MMP inhibition in cancer: Innovations for the post-trial era. Nat Rev Cancer 2: 657-672, 2002.

41. Swardfager W, Lanctôt K, Rothenburg L, Wong A, Cappell J and Herrmann N: A meta-analysis of cytokines in Alzheimer's disease. Biol Psychiat 68: 930-941, 2010.

42. Liao W, Lin JX and Leonard WJ: IL-2 family cytokines: New insights into the complex roles of IL-2 as a broad regulator of T helper cell differentiation. Curr Opin Immunol 23: 598-604, 2011. 